cular block following mivacurium. Anesthesiology 1993; 78: 1181-4.

5 Lovstad RZ, Thagaard KS, Berner NS, Raeder JC. Neostigmine 50 microg $\mathrm{kg}(-1)$ with glycopyrrolate increases postoperative nausea in women after laparoscopic gynaecological surgery. Acta Anaesthesiol Scand 2001; 45: 495-500.

\section{The incidence of failed spinal anesthe- sia, postdural puncture headache and backache is similar with Atraucan and Whitacre spinal needles}

\section{To the Editor:}

The Atraucan (AT) dual-bevelled spinal needle, which has been shown, in vitro, to cause less cerebral spinal fluid (CSF) leakage than comparable Quincke, Sprotte and Whitacre (WH) spinal needles, ${ }^{1,2}$ has been available in the United States since 1993. Three clinical studies ${ }^{3-5} \mathrm{com}^{-}$ pared the success or complication rate of AT spinal needles to pencil-point spinal needles. Vallejo et al. ${ }^{5}$ reported a higher incidence of epidural blood patch and postdural puncture headache (PDPH) associated with 26-gauge AT spinal needles compared to 25 -gauge $\mathrm{WH}$ needles. Sharma et al. ${ }^{3}$ and Andres et al. ${ }^{4}$ reported that the 26gauge AT spinal needles were technically easier to use than WH 25-gauge or 27-gauge needles and the PDPH incidences were similar. Sharma further suggested larger studies to better define PDPH and failed spinal blockade rate associated with the AT needle. We, therefore, present here our comparisons of the incidence of PDPH, postdural puncture backache (PDPB) and the failed spinal blockade rate between AT and $\mathrm{WH}$ spinal needles.

After Institutional Review Board approval and informed consent, 215 ASA I-II patients undergoing postpartum tubal ligations were randomly assigned to receive subarachnoid anesthesia with either 26-gauge AT (B. Braun Medical, Bethlehem, PA, USA; OD $0.45 \mathrm{~mm}$, length $-8.89 \mathrm{~cm}$ ) or 25 -gauge WH (BectonDickinson, Rutherford, NJ, USA; OD - $0.5 \mathrm{~mm}$, length $-8.89 \mathrm{~cm}$ ) spinal needles. Spinal needles were introduced with the midline approach at the L2-3, L3-4, or L4-5 intervertebral space. The number of attempts to successful CSF return, success rate of the spinal blockade and the handling characteristics were documented intraoperatively. Postoperatively, an investigator blinded to group assignments interviewed patients daily while in the hospital and then via telephone seven to 14 days after discharge.

The results are summarized in the Table. Incidence of PDPH was similar between AT (3.9\%) and $\mathrm{WH}$
TABLE Spinal block characteristics between AT and WH groups (differences between the groups are not significant).

\begin{tabular}{lll}
\hline & $\begin{array}{l}\text { 26-gange } \\
\text { Atraucan } \\
\text { AT Group } \\
\text { (AT) }\end{array}$ & $\begin{array}{l}\text { 25-gange } \\
\text { Whitacre } \\
\text { WH Group } \\
\text { (WH) }\end{array}$ \\
\hline $\begin{array}{ll}\text { Success with one attempt } \\
\begin{array}{l}\text { Range of number of attempts } \\
\text { needed to obtain CSF }\end{array}\end{array}$ & $\begin{array}{l}62 \% \\
\text { Average number of attempts to } 5\end{array}$ & $\begin{array}{l}61 \% \\
1 \text { to } 6\end{array}$ \\
$\begin{array}{l}\text { obtaining CSF } \\
\begin{array}{l}\text { Patient would accept same spinal } \\
\text { technique for future procedures }\end{array}\end{array}$ & $95 \%$ & $1.6 \pm 0.7$ \\
$\begin{array}{l}\text { Quality of spinal blockade } \\
\quad \text { - Adequate }\end{array}$ & $93 \%$ \\
$\quad$ - Minor supplement & $82 \%$ & \\
$\quad$ - Failed & $10.6 \%$ & $8.6 \%$ \\
$\begin{array}{l}\text { Unable to identify } \\
\text { subarachnoid space }\end{array}$ & $1.7 \%$ & $7.0 \%$ \\
\hline
\end{tabular}

$\mathrm{AT}=$ Atraucan $; \mathrm{WH}=$ Whitacre $; \mathrm{CSF}=$ cerebral spinal fluid

$(4.0 \%)$ groups. The total duration of PDPH was five days and 15 days for AT and $\mathrm{WH}$ groups respectively, but the difference in duration between groups did not reach statistical significance. Both groups had a similar one-attempt success rate of $61 \%(\mathrm{AT})$ and $62 \%(\mathrm{WH})$. The average number of attempts to obtaining CSF were $1.5 \pm 0.6$ and $1.6 \pm 0.7$ for AT and $\mathrm{WH}$ groups respectively. Incidence of PDPB was 9.6\% for AT and 9.0\% for $\mathrm{WH}$ group; and the severity was mild in both groups. The incidence of failed spinal blockade was $7.7 \%$ and $7.0 \%$ for AT and WH groups respectively. Ninety-five percent of AT group and 93\% of WH group would accept similar spinal anesthesia for future procedures.

In conclusion, we found that the 26-gauge AT and 25 -gauge WH spinal needles were associated with similar ease of clinical use and success rate, and a similarly low incidence of PDPH and mild PDPB. The choice between these two types of needles should then be based on the cost and availability of the needles.

Peter H. Pan MD MSEE

Winston-Salem, North Carolina; Richmond, Virginia

Regina Fragneto MD

Lexington, Kentucky

Charlie Moore PhD

Richmond, Virginia

Vernon Ross MD

Winston-Salem, North Carolina

Gina Justis MD

Richmond, Virginia 


\section{References}

1 Holst D, Mollmann M, Ebel C, Hausman R, Wendt M. In vitro investigation of cerebrospinal fluid leakage after dural puncture with various spinal needles. Anesth Analg 1998; 87: 1331-5.

2 Morrison LM, McCrae AF, Foo I, Scott DB, Wildsmith $J A$. An in vitro comparison of fluid leakage after dural puncture with Atraucan, Sprotte, Whitacre, and Quincke needles. Reg Anesth 1996; 21: 139-43.

3 Sharma SK, Gambling DR, Joshi GP, Sidawi JE, Herrera ER. Comparison of 26-gauge Atraucan and 25- gauge Whitacre needles: insertion characteristics and complications. Can J Anaesth 1995; 42: 706-10.

4 De Andres J, Valia JC, Errando C, Rico G, LopezAlarcon MD. Subarachnoid anesthesia in young patients: a comparative analysis of two needle bevels. Reg Anesth Pain Med 1999; 24: 547-52.

5 Vallejo MC, Mandell GL, Sabo DP, Ramanathan S. Postdural puncture headache: a randomized comparison of five spinal needles in obstetric patients. Anesth Analg 2000; 91: 916-20.

\section{Unexpected laryngoscope failure}

\section{To the Editor:}

Laryngoscope failure is a disconcerting event which occurs at the most inconvenient time and can have life threatening consequences. ${ }^{1,2}$ Common causes of failure include a failing light source, defective bulb or a faulty electrical connection. ${ }^{2}$ With aging, equipment breakage has become a serious problem. Repeated cleaning and sterilization contribute to accelerated corrosion. ${ }^{3}$ Metal fatigue from chronic use can result in sudden and unexpected breakage. ${ }^{3-5}$

The Welch Allyn laryngoscope handle and Macintosh \#3 blade (Figure) were checked prior to the induction of anesthesia for the first patient of the day. It functioned normally during the first intubation. The handle and blade were cleaned and sterilized. Prior to the induction of the second patient, an assistant noted that the hook-on assembly of the Macintosh blade could not be engaged by the head of the handle. Examination revealed that the head of the handle was missing the hinge pin and metal sleeve that forms the fulcrum to which the hook-on assembly of the blade attaches. The metal sleeve that covers the hinge pin was engaged in the slot of the locking assembly of the Macintosh blade, making it impossible to engage the blade on another laryngoscope handle until the sleeve was removed (Figure; $\mathrm{c}$ ).

Scrutiny of the head of the handle showed that the locking screw had worked loose. This screw engages the machined groove on the end of the hinge pin to secure

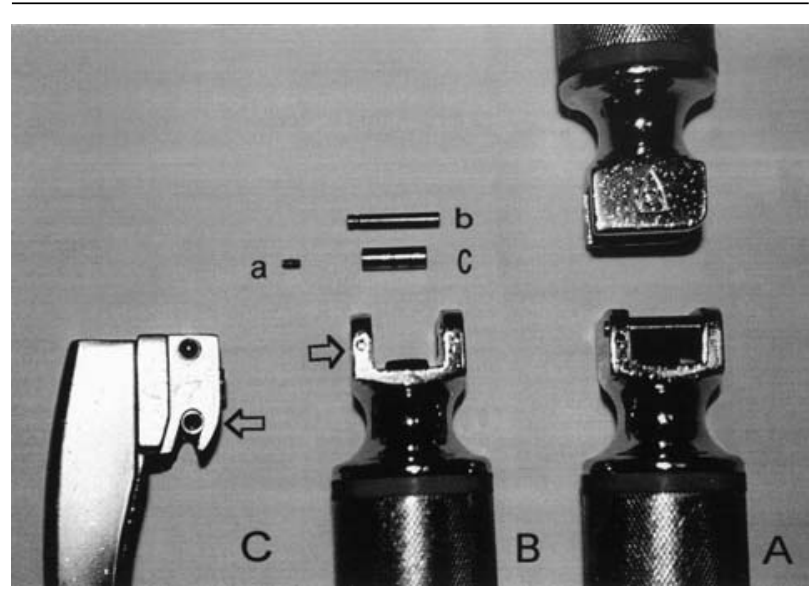

FIGURE Welch Allyn laryngoscope handles

A) Lateral and anterior view of an intact laryngoscope handle (nicks in metal finish confirm its age and usage); B) Disassembled laryngoscope head demonstrating; a) locking screw; b) hinge pin (note machined groove at the left end); c) metal sleeve (cylinder) covering of the hinge pin; the arrow indicates the location of the locking screw in the head of the handle; C) Macintosh laryngoscope blade containing the metal sleeve in the slot of the locking assembly (arrow).

and hold the pin and its sleeve in place. When the locking screw works its way free, the hinge pin can fall out. In this case, the blade was engaged by the head of the laryngoscope and used to successfully intubate the first patient. When the laryngoscope was returned to the anesthetic machine, the hinge pin fell out, leaving the metal sleeve engaged by the hook-on assembly of the blade and the head of the Welch Allyn handle devoid of the hinge pin and its accompanying metal sleeve.

Age and frequency of use have been implicated as factors contributing to the structural failure of laryngoscopes. ${ }^{3}$ Not only should the electrical integrity of the laryngoscope be checked but routine stress testing of the blade and handle as well as a careful visual inspection of older laryngoscope handles and blades are necessary. 1,5 During a rapid sequence induction, neglecting these precautions could be disastrous. Both a back up laryngoscope handle and blade should always be immediately available. ${ }^{2}$
Donald T. Jolly MD FRCP
Renee Germsheid
Blair Gallant RRT
Glenn Day RRT
Russell Harrison RRT
Ronald Amyotte RRT
Edmonton, Alberta 